Situs Jurnal : $\underline{\text { http://ejournal.stiepancasetia.ac.id/index.php/jieb }}$

Jilid 7 Nomor 1 Maret 2021

Hal 148-158

\title{
PENERAPAN MODEL ALTMAN Z-SCORE DALAM MENGUKUR POTENSI KEBANGKRUTAN (STUDI KASUS PADA PERUSAHAAN PERBANKAN BUMN YANG TERDAFTAR DI BURSA EFEK INDONESIA TAHUN 2018 \& 2019)
}

\section{Rofinus Leki}

\begin{abstract}
Abstrak: Penelitian ini bersifat sustainability research, dimana menggunakan model yang sama Altman Z-Score non manufaktur, dengan maksud untuk menguji kembali keberlanjutan kesehatan keuangan empat Bank BUMN yang parrnah diteliti penulis pada tahun 2017. Keempat perbankan dimaksud adalah Bank Negara Indonesia (Persero) Tbk PT, Bank Rakyat Indonesia (Persero) Tbk. PT, Bank Tabungan Negara (Persero) Tbk PT, Bank Mandiri (Persero) Tbk PT. Hasil penelitian menunjukan bahwa PT. Bank BTN (persero) Tbk memiliki nilai Z-score yang semakin membaik ditahun 2018 dan 2019, dibanding tahun-tahun sebelumnya yakni pada tahun 2014, 2015, 2016, dan 2017 dibawabah nilai Z-Score 1,2.. Saat ini PT. Bank BTN (Persero) Tbk., telah berpindah dari perusahaan yang berpotensi mengalami financial distress ke dalam kondisi "grey area" (membaik). Sedangkan ketiga perbankan BUMN lainnya konsisten berada dalam kategori grey area dengan nilai Z-Score diatas 1,2 tetapi dibawah nilai Z-score 2,9 Hasil penelitian ini juga menunjukan adanya perbailkan kinerja keuangan yang signifikan disetiap perbankan BUMN, namum agak menurun di tahun 2019 pada Bank BNI (Persero),Tbk. PT dan Bank BRI (Persero) Tbk.PT.. Harapannya adalah bahwa dengan adanya perbaikan kinerja keuangan secara terus menerus dan konsisten, posisi kesehatan keuangan Perbankan BUMN (persero) Tbk dapat segera berpindah ke "zona aman ".
\end{abstract}

Kata Kunci : Kesehatan Keuangan Bank BUMN, Model Altman Z-Score 


\section{PENDAHULUAN}

Bank sebagai lembaga intermediasi keuangan umumnya didirikan dengan kewenangan untuk menerima simpanan uang, meminjamkan uang, dan menerbitkan promes atau yang dikenal sebagai banknote. Menurut UU No 10 Tahun 1998, bank adalah badan usaha yang menghimpun dana dari masyarakat dalam bentuk simpanan dan menyalurkannya kepada masyarakat dalam bentuk kredit dan atau bentuk-bentuk lainnya dalam rangka meningkatkan taraf hidup orang banyak.

Jenis-jenis Perbankan di Indonesia diatur dalam Pasal 5 UU No. 7 Tahun 1992.Dalam Pasal 5 ayat (1). Perbankan di Indonesia apabila ditinjau dari segi kepemilikannya, jenis bank terdiri atas bank milik pemerintah, bank milik swasta nasional, dan bank milik swasta asing. Bank pemerintah adalah bank di mana baik akta pendirian maupun modalnya dimiliki oleh pemerintah, sehingga seluruh keuntungan bank dimiliki oleh pemerintah pula. Contohnya Bank Rakyat Indonesia (BRI), Bank Mandiri. Selain itu ada juga bank milik pemerintah daerah yang terdapat di daerah tingkat I dan tingkat II masingmasing provinsi. Contoh Bank DKI, Bank Jateng, dan sebagainya. Di Indonesia sendiri bank milik pemerintah yang sudah go public ada empat perbankan yaitu BANK NEGARA INDONESIA (PERSERO) TBK PT, BANK RAKYAT INDONESIA (PERSERO) TBK PT, BANK TABUNGAN NEGARA (PERSERO) TBK PT, BANK MANDIRI (PERSERO) TBK PT.

Perbankan milik pemerintah di Indonesia juga memiliki penaran dan fungsi yang sangat berpengaruh terhadap perekonomian Indonesia. Karena Perbankan di Indonesia memiliki fungsi sebagai penghimpun dana. Untuk menjalankan fungsinya sebagai penghimpun dana maka bank memiliki beberapa sumber yang secara garis besar ada tiga sumber yaitu Dana yang bersumber dari bank sendiri yang berupa setoran modal waktu pendirian. Dana yang berasal dari masyarakat luas yang dikumpulkan melalui usaha perbankan seperti usaha simpanan giro, deposito dan tabanas. Dana yang bersumber dari Lembaga Keuangan yang diperoleh dari pinjaman dana yang berupa Kredit Likuiditas dan Call Money (dana yang sewaktu-waktu dapat ditarik oleh bank yang meminjam) dan memenuhi persyaratan.

Mengingat pentingnya sector perbankan dalam perekonomian, informasi mengenai kejadian atau peristiwa ekonomi yang berkaitan dengan kondisi sector perbankan di Indonesia sangat perlu diketahui, khususnya mengenai informasi potensi kebangkrutan. Dengan adanya informasi tersebut akan membantu banyak pihak yang berkepentingan untuk mengevaluasi dan memperbaiki kinerja perusahaan perbankan tersebut serta mengambil tindakan yang perlu dilakukan berkaitan dengan hal tersebut.

Dasar hukum untuk penilaian kesehatan bank umum adalah Peraturan Bank Indonesia (PBI) Nomor 13/1/PBI/2011 tanggal 5 Januari 2011 tentang Penilaian Tingkat Kesehatan Bank Umum. PBI tersebut menggantikan PBI sebelumnya Nomor No. 6/10/PBI/2004 tentang Sistem Penilaian Tingkat Kesehatan Bank Umum yang telah berlaku selama hampir tujuh tahun. Petunjuk teknis pelaksanaanya mengacu ke Surat Edaran Bank Indonesia No.13/ 24 /DPNP tanggal 25 Oktober 2011.Untuk melihat indeks kesehatan bank berdasarkan rasio CAMEL (Capital, Asset Quality, Management, Earning, Liquidity)

Selain menggunkan Peraturan Bank Indonesia (PBI) Nomor 13/1/PBI/2011 tanggal 5 Januari 2011, untuk mengetahui tingkat kesehatan bank juga dapat dilakukan juga dengan menggunakan metode multiple discriminan analysis (MDA) yang dikemukakan oleh Altman (1968) dan metode analisismultidiskriminan yang dikemukakan oleh Springate (1978). 
Metode Multiple Discriminant Analysis (MDA) adalah suatu metode yang digunakan Altman untuk memprediksi kebangkrutan suatu perusahaan dengan menggunakan lima jenis rasio keuangan yaitu working capital to total asset, retained earning to total asset, earning before interest and taxes to total asset, market value of equity to book value of total debts, dan sales to total asset. Dalam metode Altman Z-Score rasio-rasio tersebut merupakan rasio yang mendeteksi kondisi keuangan perusahaan yang berkaitan dengan likuiditas, profitabilitas dan aktivitas perusahaan. Dengan adanya kombinasi rasio-rasio tersebut model Altman Z-Score akan sangat membantu manajemen dalam memprediksi potensi kebangkrutan yang mungkin akan dialami oleh perusahaan.

Penelitian ini merupakan penelitian lanjutan dari penelitian yang telah dilakukan pada tahun 2017 oleh peneliti. Tujuannya untuk mendeteksi apakah telah ada perbaikan dan peningkatan kinerja keuangan atau kesehatan keuangan dari keempat Bank BUMN tersebut yang ratarata pada tahun penelitian tersebut berada pada area grey dan bahkan salah satu berada pada area potensi kebangkrutan.

Bagi manajemen dan pihak lain terkait, memprediksi mengenai potensi kebangkrutan sangat penting sebagai bahan evaluasi kinerja perusahaan yang selama ini terjadi. Sehingga dapat diambil suatu kebijakan untuk memperbaiki kondisi dan kinerja perusahaannya.

\section{Rumusan Masalah}

Berdasarkan uraian dalam latar belakang masalah, maka rumusan masalah dari penelitian ini adalah

1. Bagaimana hasil dari prediksi potensi kebangkrutan perusahaan perbankan BUMN yang terdaftar di Bursa Efek Indonesia tahun 2018 sampai tahun 2019 dengan menggunakan formula model Altman Z Score non manufaktur.
2. Rasio apa saja yang membuat Perusahaan Perbankan BUMN dikategorikan sehat atau berpotensi bangkrut.

\section{KAJIAN LITERATUR}

\section{a. Analisa Laporan Keuangan}

Analisa laporan keuangan penting dilakukan untuk mengetahui kekuatan dan kelemahan suatu perusahaan. Informasi ini diperlukan untuk mengevaluasi kinerja yang dicapai manajemen perusahaan di masa yang lalu, dan juga untuk bahan pertimbangan dalam menyusun rencana perusahaan kedepan. Salah satu cara memperoleh informasi yang bermanfaat dari laporan keuangan perusahaan adalah dengan melakukan analisis rasio keuangan (Sudana 2011:20).

\section{b. Laporan Keuangan}

Menurut Hery (2012) Laporan keuangan pada dasarnya adalah hasil dari proses akuntansi yang dapat digunakan sebagai alat untuk mengkomunikasikan data keuangan atau aktivitas perusahaan kepada pihakpihak yang berkepentingan.

\section{c. Pengertian Kebangkrutan}

$$
\text { Menurut Rizki }
$$

Kebangkrutan merupakan kegagalan perusahaan dalam menjalankan operasi perusahaan untuk menghasilkan laba..

\section{d. Pengertian Bank}

Menurut Kasmir (2011 : 4) Bank merupakan perusahaan keuangan yang bergerak dalam memberikan layanan keuangan yang mengandalkan kepercayaan dari masyarakat dalam mengelola dananya. Bank merupakan tempat perusahaan menyimpan uang atau menitipkan uangnya dalam bentuk simpanan.

\section{e. Penilaian Kesehatan Bank}

Berdasarkan Undang-undang
Nomor 10 tahun 1998 tentang
Perbankan atas Undang-undang Nomor
7 tahun 1992 tentang Perbankan, Bank
wajib memelihara tingkat kesehatan
bank sesuai dengan ketentuan


kecukupan modal, kualitas aset, kualitas manajemen, likuiditas, rentabilitas, solvabilitas, dan aspek lain yang berhubungan dengan usaha bank, dan wajib melakukan kegiatan usaha sesuai dengan prinsip kehati-hatian.

Dasar hukum penilaian kesehatan bank tertera pada Peraturan Bank Indonesia (PBI) Nomor 13/1/PB/2011 tanggal 5 Januari 2011 tentang Penilaian Kesehatan Bank Umum. Indikator penilai tingkat kesehatan bank tersebut tertera pada Surat Edaran Bank Indonesia Nomor 13/24/DPNP Tanggal 25 Oktober 2011.

\section{f. Model Prediksi Kebangkrutan Altman Z-Score}

Menurut Abu Kholid (2012) ZScore adalah skor yang ditentukan dari hitungan standar kali nisbah-nisbah keuangan yang menunjukkan tingkat kemungkinan kebangkrutan perusahaan. Formula Z-Score untuk memprediksi kebangkrutan dari Altman merupakan sebuah multivariate formula yang digunakan untuk mengukur kesehatan finansial dari sebuah perusahaan.

Formula Z-score untuk perusahaan jenis manufaktur dan non-manufaktur dibedakan sebagai berikut:

1). Untuk perusahaan manufaktur, menggunakan formula yang terdiri dari 5 koefisien, yakni:

$$
\begin{gathered}
\mathrm{Z}=\mathbf{0 , 7 1 7} \mathrm{X}_{\mathbf{1}}+\mathbf{0 , 8 4 7} \mathrm{X}_{\mathbf{2}}+\mathbf{3 , 1 0 7} \\
\mathrm{X}_{\mathbf{3}}+\mathbf{0 , 4 2 0} \mathrm{X}_{4}+ \\
\mathbf{0 , 9 9 8} \mathrm{X}_{\mathbf{5}}
\end{gathered}
$$

2). Untuk perusahaan non-manufaktur, menggunakan formula yang terdiri dari 4 koefisien, yakni:

$$
\begin{gathered}
\mathrm{Z}=\underset{1,05 X_{4}}{6,56} X_{1}+3,26 X_{2}+6,72 X_{3}+ \\
1,
\end{gathered}
$$

\section{METODOLOGI PENELITIAN}

\section{Jenis, Sumber dan Teknik Pengumpulan Data}

Jenis data yang digunakan adalah data kuantitatif, yang berbentuk laporan keuangan perusahaan Perbankan selama tahun 2018 sampai dengan 2019. Sedangakan sumber data diperoleh dari Bursa Efek Indonesia (Idx).

\section{Populasi dan Sampel}

Populasi dan Sampel dalam penelitian ini adalah Perusahaan Perbankan BUUMN yang terdaftar di Bursa Efek Indonesia tahun 2018 sampai 2019 yang terdiri dari :

1). PT Bank Rakyat Indonesia (Persero) Tbk

2). PT Bank Negara Indonesia (Persero) Tbk

3). PT Bank Tabungan Negara (Persero)Tbk

4). PT Bank Mandiri (Persero) Tbk

\section{Teknik Analisa dan Pengolahan Data}

Menggunakan Metode Altman Z - Score Untuk Non Manufaktur dengan formula sbb

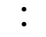

$$
\begin{aligned}
& \begin{array}{c}
\text { Z-Score }=\text { 6,56WC/TA + 3,26RE/TA + } \\
6,72 \mathrm{EBIT} / \mathrm{TA}+1,05 \mathrm{MVE} / \mathrm{BVD}
\end{array} \\
& \text { Keterangan: } \\
& \text { - WC : Working Capital } \\
& \text { - TA : Total Assets } \\
& \text { - RE : Retained Earning } \\
& \text { - EBIT : Earning Before Interst } \\
& \text { and Taxes } \\
& \text { - MVE : Market Value Equity } \\
& \text { - BVD : Book Value of Total Dept }
\end{aligned}
$$
menjadi tiga tingkatan yaitu : 
perusahaan berada dalam daerah kelabu (grey area)

c. Apabila nilai Z-Score dibawah 1,20 (Z-Score < 1,20) diklasifikasikan sebagai perusahaan yang berpotensi bangkrut.

\section{HASIL PENELITIAN DAN PEMBAHASAN}

Perhitungan rasio Altman Z-Score Non Manufaktur pada Perusahaan Perbankan BUMN yang terdaftar di Bursa Efek Indonesia tahun 2018 dan tahun 2019 adalah sebaagi berikut :

\section{A. Working Capital Assets toTotal Assets ( $\left.\mathbf{X}_{1}\right)$}

Rasio ini digunakan untuk mengukur kemampuan perusahaan dalam memenuhi kewajiban lancar atau jangka pendeknya dari total aktiva dan posisi modal kerja. Dimana modal kerja (Gross working capital) adalah total aktiva lancer dikurangkan dengan total utang lancar. Sedangkan total aset adalah total aktiva perusahaan.

Variabel X1 diperoleh dengan rumus berikut :

$$
X 1=\frac{\text { Working Capital }}{\text { Total Assets }}
$$

\section{Tabel 1 : Perhitungan $X_{1}$ Perusahaan Perbankan BUMN tahun 2018 dan tahun 2019}

\begin{tabular}{|c|c|c|}
\hline NAMA BANK & $\begin{array}{c}\text { WOR } \\
\text { KING } \\
\text { CAPIT } \\
\text { AL / } \\
\text { TOTA } \\
\text { L } \\
\text { ASSET }\end{array}$ & $\begin{array}{c}\text { X1 } \\
\text { TAHUN } \\
2018\end{array}$ \\
\hline $\begin{array}{l}\text { BANK NEGARA INDONESIA } \\
\text { (PERSERO) TBK, PT }\end{array}$ & $\begin{array}{l}210.562 .14 \mathrm{~S} \\
808.572 .011\end{array}$ & 0,26041 \\
\hline $\begin{array}{l}\text { BANK RAKYAT INDONESIA } \\
\text { (PERSERO) TBK, PT }\end{array}$ & \begin{tabular}{r|}
$\frac{300.585 .25}{1.296 .898 .2}$ \\
\end{tabular} & 0,23177 \\
\hline $\begin{array}{l}\text { BANK TABUNGAN NEGARA } \\
\text { (PERSERO) TBK, PT }\end{array}$ & \begin{tabular}{r|}
87.333 .583 \\
306.436 .184
\end{tabular} & 0,28500 \\
\hline $\begin{array}{l}\text { BANK MANDIRI (PERSERO) } \\
\text { TBK, PT }\end{array}$ & $\frac{\mathbf{3 5 1 . 0 4 3 . 4}}{1.202 .252 .0}$ & 0,29199 \\
\hline NAMA BANK & $\begin{array}{c}\text { WOR } \\
\text { KING } \\
\text { CAPIT } \\
\text { AL / } \\
\text { TOTA } \\
\text { L } \\
\text { ASSET }\end{array}$ & $\begin{array}{c}\text { X1 } \\
\text { TAHUN } \\
2019\end{array}$ \\
\hline $\begin{array}{l}\text { BANK NEGARA INDONESIA } \\
\text { (PERSERO) TBK, PT }\end{array}$ & $\frac{218.333 .400}{845.606 .208}$ & 0,25820 \\
\hline $\begin{array}{l}\text { BANK RAKYAT INDONESIA } \\
\text { (PERSERO) TBK, PT }\end{array}$ & $\frac{307.190 .156}{1.416 .758 .840}$ & 0,21683 \\
\hline $\begin{array}{l}\text { BANK TABUNGAN NEGARA } \\
\text { (PERSERO) TBK, PT }\end{array}$ & $\frac{99.158 .567}{311.776 .828}$ & 0,31804 \\
\hline $\begin{array}{l}\text { BANK MANDIRI (PERSERO) } \\
\text { TBK, PT }\end{array}$ & $\frac{382.935 .426}{1.318 .246 .355}$ & 0,29049 \\
\hline
\end{tabular}

Sumber : Data Diolah

B. Retained Earning to Total Assets $\left(\mathbf{X}_{2}\right)$

Rasio ini digunakan untuk mendeteksi atau mengukur kemampuan perusahaan dalam menghasilkan keuntungan dalam periode tertentu. Manajemen bank sangat berkepentingan untuk dapat melihat rasio ini, guna mengetahui tingkat efisiensi usaha dan kemampuan perusahaan dalam memperoleh laba dari hasil penjualannya.

Ratio X2 diperoleh dengan rumus berikut :

$X 2=\frac{\text { Retained Earning }}{\text { TotalAssets }}$ 


\section{Tabel 2 : Perhitungan $\mathbf{X}_{2}$ Perusahaan Perbankan BUMN tahun 2018 dan tahun 2019}

\begin{tabular}{|c|c|c|}
\hline NAMA BANK & $\begin{array}{c}\text { RETAI } \\
\text { NED } \\
\text { EARNI } \\
\text { NG / } \\
\text { TOTAL } \\
\text { ASSET }\end{array}$ & $\begin{array}{c}\text { X2 } \\
\text { TAHUN } \\
2018\end{array}$ \\
\hline $\begin{array}{l}\text { BANK NEGARA INDONESIA } \\
\text { (PERSERO) TBK, PT }\end{array}$ & $\frac{71.047 .00}{808.572 .0}$ & 0,08787 \\
\hline $\begin{array}{l}\text { BANK RAKYAT INDONESIA } \\
\text { (PERSERO) TBK, PT }\end{array}$ & \begin{tabular}{r|}
28.941 .0 \\
1.296 .898
\end{tabular} & 0,02232 \\
\hline $\begin{array}{l}\text { BANK TABUNGAN NEGARA } \\
\text { (PERSERO) TBK, PT }\end{array}$ & $\frac{2.783 .000}{306.436 .0}$ & 0,00908 \\
\hline $\begin{array}{l}\text { BANK MANDIRI (PERSERO) } \\
\text { TBK, PT }\end{array}$ & $\begin{array}{r}24.535 .0 \\
1.202 .252\end{array}$ & 0,02041 \\
\hline NAMA BANK & $\begin{array}{l}\text { RETAI } \\
\text { NED } \\
\text { EARNI } \\
\text { NG / } \\
\text { TOTAL } \\
\text { ASSET }\end{array}$ & $\begin{array}{c}\text { X2 } \\
\text { TAHUN } \\
2019\end{array}$ \\
\hline $\begin{array}{l}\text { BANK NEGARA INDONESIA } \\
\text { (PERSERO) TBK, PT }\end{array}$ & $\frac{82.464 .000}{845.606 .000}$ & 0,09752 \\
\hline $\begin{array}{l}\text { BANK RAKYAT INDONESIA } \\
\text { (PERSERO) TBK, PT }\end{array}$ & $\frac{39.499 .000}{1.416 .759 .00}$ & 0,02788 \\
\hline $\begin{array}{l}\text { BANK TABUNGAN NEGARA } \\
\text { (PERSERO) TBK, PT }\end{array}$ & $\frac{557.000}{311.777 .000}$ & 0,01788 \\
\hline $\begin{array}{l}\text { BANK MANDIRI (PERSERO) } \\
\text { TBK, PT }\end{array}$ & $\begin{array}{r}\frac{35.667 .000}{1.318 .246 .00} \\
\end{array}$ & 0,02706 \\
\hline
\end{tabular}

Sumber : Data diolah

\section{Earning Before Interest and Taxes (EBIT) toTotal Assets $\left(\mathbf{X}_{3}\right)$}

Rasio ini digunaakan untuk mengetahui kemampuan perusahaan dalam menghasilkan laba dari aktiva perusahaan, sebelum pembayaran bunga dan pajak. Melemahnya faktor ini merupakan indikator terbaik akan hadirnya kebangkrutan. Berikut adalah EBIT perussahaan tahun 2018 dan tahun 2019.

Ratio X3 diperoleh dengan peersamaan berikut :

$$
X 3=\frac{\text { EBIT }}{\text { TotalAssets }}
$$

\section{Tabel 3 : Perhitungan $\mathrm{X}_{3}$ Perusahaan Perbankan BUMN tahun 2018 dan tahun 2019}

\begin{tabular}{|c|c|c|}
\hline NAMA BANK & $\begin{array}{c}\text { EBIT / } \\
\text { TOTAL } \\
\text { ASSET }\end{array}$ & $\begin{array}{c}\text { X3 } \\
\text { TAHUN } \\
2018\end{array}$ \\
\hline $\begin{array}{l}\text { BANK NEGARA INDONESIA } \\
\text { (PERSERO) TBK, PT }\end{array}$ & $\frac{19.599 .000}{808.572 .00}$ & 0,02424 \\
\hline $\begin{array}{l}\text { BANK RAKYAT INDONESIA } \\
\text { (PERSERO) TBK, PT }\end{array}$ & \begin{tabular}{r|}
41.726 .00 \\
1.296 .898$.
\end{tabular} & 0,03217 \\
\hline $\begin{array}{l}\text { BANK TABUNGAN NEGARA } \\
\text { (PERSERO) TBK, PT }\end{array}$ & $\frac{3.594 .000}{306.436 .00}$ & 0,01173 \\
\hline $\begin{array}{l}\text { BANK MANDIRI (PERSERO) } \\
\text { TBK, PT }\end{array}$ & \begin{tabular}{r|}
33.096 .00 \\
1.202 .252$.
\end{tabular} & 0,02753 \\
\hline NAMA BANK & $\begin{array}{l}\text { EBIT / } \\
\text { TOTAL } \\
\text { ASSET }\end{array}$ & $\begin{array}{c}\text { X3 } \\
\text { TAHUN } \\
2019\end{array}$ \\
\hline $\begin{array}{l}\text { BANK NEGARA INDONESIA } \\
\text { (PERSERO) TBK, PT }\end{array}$ & $\frac{19.487 .00}{845.606 .00}$ & 0,02305 \\
\hline $\begin{array}{l}\text { BANK RAKYAT INDONESIA } \\
\text { (PERSERO) TBK, PT }\end{array}$ & $\begin{aligned} 41.726 .00 \\
1.416 .759 .\end{aligned}$ & 0,02945 \\
\hline $\begin{array}{l}\text { BANK TABUNGAN NEGARA } \\
\text { (PERSERO) TBK, PT }\end{array}$ & \begin{tabular}{r|}
522.000 \\
311.777 .00
\end{tabular} & 0,00167 \\
\hline $\begin{array}{l}\text { BANK MANDIRI (PERSERO) } \\
\text { TBK, PT }\end{array}$ & \begin{tabular}{r|}
36.452 .00 \\
1.318 .246$.
\end{tabular} & 0,02765 \\
\hline
\end{tabular}

Sumber : Data Diolah

D. Market Value of Equity to Book Value of Total Liabilities $\left(\mathrm{X}_{4}\right)$

Rasio ini menunjukkan kemampuan perusahaan untuk memenuhi kewajibankewajiban dari nilai pasar modal sendiri (saham biasa). Nilai pasar ekuitas sendiri diperoleh dengan mengalikan jumlah lembar saham biasa yang beredar dengan harga pasar per lembar saham biasa (close review). Nilai buku hutang adalah total hutang perusahaan.

Berikut ini akan diperlihatkan jumlah lembar saham dan harga pasar saham per lembar saham biasa (Close Preview).

\section{Market Value of Equit $=($ Jumlah lembar saham $) \mathrm{X}$ (Harga saham $)$}


Tabel 4 : Jumlah Saham yang berredar pada akhir tahun dan Close preview

Tahun 2018 dan tahun 2019

\begin{tabular}{|c|c|c|c|}
\hline NAMA BANK & $\begin{array}{c}\text { JUMLAH } \\
\text { LEMBAR } \\
\text { SAHAM } \\
2018 \\
\end{array}$ & $\begin{array}{c}\text { CLOSE } \\
\text { PREVIE } \\
\text { W } 2018 \\
\end{array}$ & $\begin{array}{c}\text { Market } \\
\text { Value of } \\
\text { Equity to } \\
\text { Book Value } \\
2018\end{array}$ \\
\hline $\begin{array}{l}\text { BANK } \\
\text { NEGARA } \\
\text { INDONESIA } \\
\text { (PERSERO) } \\
\text { TBK, PT } \\
\end{array}$ & $\begin{array}{l}18.624 .947 \\
.000\end{array}$ & $\begin{array}{l}\mathrm{Rp} \\
8.800\end{array}$ & $\begin{array}{r}163.899 .533 \\
600.000 \\
\end{array}$ \\
\hline $\begin{array}{l}\text { BANK } \\
\text { RAKYAT } \\
\text { INDONESIA } \\
\text { (PERSERO) } \\
\text { TBK, PT } \\
\end{array}$ & $\begin{array}{l}122.595 .34 \\
7.000\end{array}$ & $\begin{array}{l}\mathrm{Rp} \\
3.660 \\
\end{array}$ & $\begin{array}{r}448.698 .970 \\
020.000 \\
\end{array}$ \\
\hline $\begin{array}{l}\text { BANK } \\
\text { TABUNGAN } \\
\text { NEGARA } \\
\text { (PERSERO) } \\
\text { TBK, PT } \\
\end{array}$ & $\begin{array}{l}10.588 .250 \\
.000\end{array}$ & $\begin{array}{l}\mathrm{Rp} \\
2.540\end{array}$ & $\begin{array}{r}26.894 .155 .0 \\
00.000 \\
\end{array}$ \\
\hline $\begin{array}{l}\text { BANK } \\
\text { MANDIRI } \\
\text { (PERSERO) } \\
\text { TBK, PT } \\
\end{array}$ & $\begin{array}{l}46.666 .667 \\
.000\end{array}$ & $\begin{array}{l}\mathrm{Rp} \\
7.375\end{array}$ & $\begin{array}{r}174.300 .001 \\
245.000 \\
\end{array}$ \\
\hline NAMA BANK & $\begin{array}{c}\text { JUMLAH } \\
\text { LEMBAR } \\
\text { SAHAM } \\
2019 \\
\end{array}$ & $\begin{array}{l}\text { CLOSE } \\
\text { PREVIE } \\
\text { W } 2019 \\
\end{array}$ & $\begin{array}{c}\text { Market } \\
\text { Value of } \\
\text { Equity to } \\
\text { Book Value } \\
2019\end{array}$ \\
\hline $\begin{array}{l}\text { BANK } \\
\text { NEGARA } \\
\text { INDONESIA } \\
\text { (PERSERO) } \\
\text { TBK, PT }\end{array}$ & $\begin{array}{l}18.624 .947 \\
.000\end{array}$ & $\begin{array}{l}\mathrm{Rp} \\
7.850\end{array}$ & $\begin{array}{r}146.205 .833 \\
950.000 \\
\end{array}$ \\
\hline $\begin{array}{l}\text { BANK } \\
\text { RAKYAT } \\
\text { INDONESIA } \\
\text { (PERSERO) } \\
\text { TBK, PT } \\
\end{array}$ & $\begin{array}{l}122.595 .34 \\
7.000\end{array}$ & $\begin{array}{l}\mathrm{Rp} \\
4.400 \\
\end{array}$ & $\begin{array}{r}539.419 .526 \\
800.000 \\
\end{array}$ \\
\hline $\begin{array}{l}\text { BANK } \\
\text { TABUNGAN } \\
\text { NEGARA } \\
\text { (PERSERO) } \\
\text { TBK, PT }\end{array}$ & $\begin{array}{l}10.588 .250 \\
.000\end{array}$ & $\begin{array}{l}\mathrm{Rp} \\
2.120\end{array}$ & $\begin{array}{r}22.447 .090 .0 \\
00.000 \\
\end{array}$ \\
\hline $\begin{array}{l}\text { BANK } \\
\text { MANDIRI } \\
\text { (PERSERO) } \\
\text { TBK, PT }\end{array}$ & $\begin{array}{l}46.666 .667 \\
.000\end{array}$ & $\begin{array}{l}\mathrm{Rp} \\
7.675\end{array}$ & $\begin{array}{r}358.166 .669 \\
225.000\end{array}$ \\
\hline
\end{tabular}

Sumber : idx.co.id

Ratio X4 diperoleh dengan persamaan berikut :

$$
X 4=\frac{\text { Market Value of Equity }}{\text { Total Liabilities }}
$$

Tabel 5 : Perhitungan Rasio $\mathrm{X}_{4}$ Perusahaan Perbankan BUMN tahun 2018 dan tahun 2019

\begin{tabular}{|c|c|c|c|}
\hline NAMA BANK & $\begin{array}{c}\text { Market Value } \\
\text { of Equity to } \\
\text { Book Value } \\
2018\end{array}$ & $\begin{array}{c}\text { TOTAL } \\
\text { LIABILI } \\
\text { TIES } \\
2018 \\
\end{array}$ & $\begin{array}{c}\text { X4 } \\
\text { Tahu } \\
\text { n } \\
2018\end{array}$ \\
\hline $\begin{array}{l}\text { BANK NEGARA } \\
\text { INDONESIA } \\
\text { (PERSERO) TBK, } \\
\text { PT }\end{array}$ & 163.900 .000$. & $\begin{array}{l}671.238 .0 \\
00\end{array}$ & $\begin{array}{c}0,244 \\
18\end{array}$ \\
\hline $\begin{array}{l}\text { BANK RAKYAT } \\
\text { INDONESIA } \\
\text { (PERSERO) TBK, } \\
\text { PT }\end{array}$ & 448.699.000. & $\begin{array}{l}1.090 .664 \\
.000\end{array}$ & $\begin{array}{c}0,411 \\
400\end{array}$ \\
\hline $\begin{array}{l}\text { BANK } \\
\text { TABUNGAN } \\
\text { NEGARA } \\
\text { (PERSERO) TBK, } \\
\text { PT } \\
\end{array}$ & 26.894 .000$. & $\begin{array}{l}282.596 .0 \\
00\end{array}$ & $\begin{array}{c}\mathbf{0 , 0 9 5} \\
17\end{array}$ \\
\hline $\begin{array}{l}\text { BANK MANDIRI } \\
\text { (PERSERO) TBK, } \\
\text { PT }\end{array}$ & 174.300 .000 & $\begin{array}{l}941.953 .0 \\
00\end{array}$ & $\begin{array}{c}\mathbf{0 , 1 9 0} \\
\mathbf{5 0}\end{array}$ \\
\hline NAMA BANK & $\begin{array}{c}\text { Market Value } \\
\text { of Equity to } \\
\text { Book Value } \\
2019 \\
\end{array}$ & $\begin{array}{c}\text { TOTAL } \\
\text { LIABILI } \\
\text { TIES } \\
2019 \\
\end{array}$ & $\begin{array}{c}\text { X4 } \\
\text { Tahu } \\
\text { n } \\
\mathbf{2 0 1 9} \\
\end{array}$ \\
\hline $\begin{array}{l}\text { BANK NEGARA } \\
\text { INDONESIA } \\
\text { (PERSERO) TBK, } \\
\text { PT }\end{array}$ & 146.206.000. & $\begin{array}{l}688.489 .0 \\
00\end{array}$ & $\begin{array}{c}0,212 \\
36\end{array}$ \\
\hline $\begin{array}{l}\text { BANK RAKYAT } \\
\text { INDONESIA } \\
\text { (PERSERO) TBK, } \\
\text { PT }\end{array}$ & 539.420 .000$. & $\begin{array}{l}1.183 .156 \\
.000\end{array}$ & $\begin{array}{c}\mathbf{0 , 4 5 5} \\
92\end{array}$ \\
\hline $\begin{array}{l}\text { BANK } \\
\text { TABUNGAN } \\
\text { NEGARA } \\
\text { (PERSERO) TBK, } \\
\text { PT }\end{array}$ & 22.448 .000 . & $\begin{array}{l}287.941 .0 \\
00\end{array}$ & $\begin{array}{c}\mathbf{0 , 0 7 7} \\
96\end{array}$ \\
\hline $\begin{array}{l}\text { BANK MANDIRI } \\
\text { (PERSERO) TBK, } \\
\text { PT }\end{array}$ & 358.167.000. & $\begin{array}{l}1.025 .745 \\
.000\end{array}$ & $\begin{array}{c}0,349 \\
18\end{array}$ \\
\hline
\end{tabular}

\section{Sumber : Data Diolah}

Dari data di atas maka dapat ditetukan rasio $\mathrm{X} 1, \mathrm{X} 2, \mathrm{X} 3$ dan X4 dan dapat dimasukan ke dalam formula Z-Score Non Manufaktur untuk Perbankan BUMN tahun 2018 dan tahun 2019 dengan rincian perhitungan sebagai berikut:

Z-Score $=6,56 X_{1}+3,26 X_{2}+6,72 X_{3}+$ $1,05 \mathrm{X}_{4}$ 
Tabel 6 : Perhitungan Metode Altman Z-Score Non Manufaktur Perusahaan Perbankan BUMN tahun 2018 dan tahun 2019

\begin{tabular}{|c|c|c|c|c|c|}
\hline NAMA BANK & $\begin{array}{l}6,5 \\
6(X \\
1)\end{array}$ & $\begin{array}{c}3,2 \\
6(X \\
2)\end{array}$ & $\begin{array}{c}6,7 \\
2(X \\
3)\end{array}$ & $\begin{array}{c}1,0 \\
5(X \\
4)\end{array}$ & $\begin{array}{c}\mathrm{Z} \\
\text { SC } \\
\text { OR } \\
\text { E } \\
\text { TA } \\
\text { HU } \\
\text { N } \\
201 \\
8\end{array}$ \\
\hline $\begin{array}{l}\text { BANK NEGARA } \\
\text { INDONESIA } \\
\text { (PERSERO) TBK, PT }\end{array}$ & $\begin{array}{l}1.7 \\
1\end{array}$ & $\begin{array}{r}0,2 \\
9\end{array}$ & $\begin{array}{r}0.1 \\
6\end{array}$ & $\begin{array}{c}0.2 \\
6\end{array}$ & $\begin{array}{r}2.4 \\
2\end{array}$ \\
\hline $\begin{array}{l}\text { BANK RAKYAT } \\
\text { INDONESIA } \\
\text { (PERSERO) TBK, PT }\end{array}$ & $\begin{array}{l}1.5 \\
2\end{array}$ & $\begin{array}{r}0.0 \\
7\end{array}$ & $\begin{array}{r}0.2 \\
2\end{array}$ & $\begin{array}{c}0.4 \\
3\end{array}$ & $\begin{array}{r}2.2 \\
4\end{array}$ \\
\hline $\begin{array}{l}\text { BANK TABUNGAN } \\
\text { NEGARA (PERSERO) } \\
\text { TBK, PT }\end{array}$ & $\begin{array}{l}1.8 \\
6\end{array}$ & $\begin{array}{r}0.0 \\
3\end{array}$ & $\begin{array}{r}0.0 \\
8\end{array}$ & 0.1 & $\begin{array}{r}2.0 \\
7\end{array}$ \\
\hline $\begin{array}{l}\text { BANK MANDIRI } \\
\text { (PERSERO) TBK, PT }\end{array}$ & $\begin{array}{l}1.9 \\
4\end{array}$ & $\begin{array}{r}0.0 \\
7\end{array}$ & $\begin{array}{r}0.1 \\
9\end{array}$ & $\begin{array}{c}0.2 \\
0\end{array}$ & $\begin{array}{r}2.4 \\
0\end{array}$ \\
\hline NAMA BANK & $\begin{array}{c}6,5 \\
6(X \\
1)\end{array}$ & $\begin{array}{c}3,2 \\
6(X \\
2)\end{array}$ & $\begin{array}{l}6,7 \\
2(X \\
3)\end{array}$ & $\begin{array}{c}1,0 \\
5(X \\
4)\end{array}$ & $\begin{array}{c}\text { Z } \\
\text { SC } \\
\text { OR } \\
\text { E } \\
\text { TA } \\
\text { HU } \\
\text { N } \\
201 \\
9\end{array}$ \\
\hline $\begin{array}{l}\text { BANK NEGARA } \\
\text { INDONESIA } \\
\text { (PERSERO) TBK, PT }\end{array}$ & $\begin{array}{l}1.6 \\
9\end{array}$ & $\begin{array}{r}0.3 \\
2\end{array}$ & $\begin{array}{r}0.1 \\
5\end{array}$ & $\begin{array}{c}0.2 \\
2\end{array}$ & $\begin{array}{r}2.3 \\
8\end{array}$ \\
\hline $\begin{array}{l}\text { BANK RAKYAT } \\
\text { INDONESIA } \\
\text { (PERSERO) TBK, PT }\end{array}$ & $\begin{array}{l}1.4 \\
2\end{array}$ & $\begin{array}{r}0.0 \\
9\end{array}$ & $\begin{array}{r}0.2 \\
0\end{array}$ & $\begin{array}{c}0.4 \\
8\end{array}$ & $\begin{array}{r}2.1 \\
9\end{array}$ \\
\hline $\begin{array}{l}\text { BANK TABUNGAN } \\
\text { NEGARA (PERSERO) } \\
\text { TBK, PT }\end{array}$ & $\begin{array}{l}2.0 \\
8\end{array}$ & $\begin{array}{r}0.0 \\
6\end{array}$ & $\begin{array}{r}0.0 \\
1\end{array}$ & $\begin{array}{c}0.0 \\
8\end{array}$ & $\begin{array}{r}2.2 \\
3\end{array}$ \\
\hline $\begin{array}{l}\text { BANK MANDIRI } \\
\text { (PERSERO) TBK, PT }\end{array}$ & $\begin{array}{l}1.9 \\
1\end{array}$ & $\begin{array}{r}0.0 \\
9\end{array}$ & $\begin{array}{r}0.1 \\
9\end{array}$ & $\begin{array}{c}0.3 \\
7\end{array}$ & $\begin{array}{r}2.5 \\
6\end{array}$ \\
\hline
\end{tabular}

Sumber: Data Diolah

Setelah diproleh nilai dari Z-Score, maka dapat diperoleh hasil sebagai berikut :
Tabel 7 : Hasil Metode Altman Z-Score Non Manufaktur pada Perusahaan Perbankan BUMN tahun 2018 dan tahun 2019

\begin{tabular}{|c|c|c|}
\hline NAMA BANK & $\begin{array}{c}Z \\
\text { SCO } \\
\text { RE } \\
\text { TAH } \\
\text { UN } \\
2018 \\
\end{array}$ & $\begin{array}{l}\text { KETERA } \\
\text { NGAN }\end{array}$ \\
\hline $\begin{array}{l}\text { BANK NEGARA INDONESIA } \\
\text { (PERSERO) TBK, PT }\end{array}$ & 2.42 & $\begin{array}{l}\text { GREY } \\
\text { AREA } \\
\end{array}$ \\
\hline $\begin{array}{l}\text { BANK RAKYAT INDONESIA } \\
\text { (PERSERO) TBK, PT }\end{array}$ & 2.24 & $\begin{array}{l}\text { GREY } \\
\text { AREA }\end{array}$ \\
\hline $\begin{array}{l}\text { BANK TABUNGAN NEGARA } \\
\text { (PERSERO) TBK, PT }\end{array}$ & 2.07 & $\begin{array}{l}\text { GREY } \\
\text { AREA }\end{array}$ \\
\hline $\begin{array}{l}\text { BANK MANDIRI (PERSERO) } \\
\text { TBK, PT }\end{array}$ & 2.40 & $\begin{array}{l}\text { GREY } \\
\text { AREA }\end{array}$ \\
\hline NAMA BANK & $\begin{array}{c}Z \\
\text { SCO } \\
\text { RE } \\
\text { TAH } \\
\text { UN } \\
2019 \\
\end{array}$ & $\begin{array}{l}\text { KETERA } \\
\text { NGAN }\end{array}$ \\
\hline $\begin{array}{l}\text { BANK NEGARA INDONESIA } \\
\text { (PERSERO) TBK, PT }\end{array}$ & 2.38 & $\begin{array}{l}\text { GREY } \\
\text { AREA } \\
\end{array}$ \\
\hline $\begin{array}{l}\text { BANK RAKYAT INDONESIA } \\
\text { (PERSERO) TBK, PT }\end{array}$ & 2.19 & $\begin{array}{l}\text { GREY } \\
\text { AREA }\end{array}$ \\
\hline $\begin{array}{l}\text { BANK TABUNGAN NEGARA } \\
\text { (PERSERO) TBK, PT }\end{array}$ & 2.23 & $\begin{array}{l}\text { GREY } \\
\text { AREA }\end{array}$ \\
\hline $\begin{array}{l}\text { BANK MANDIRI (PERSERO) } \\
\text { TBK, PT }\end{array}$ & 2.56 & $\begin{array}{l}\text { GREY } \\
\text { AREA }\end{array}$ \\
\hline
\end{tabular}

Sumber : Data diolah

\section{Pembahasan}

Dasar hukum penilaian kesehatan bank tertera pada Peraturan Bank Indonesia (PBI) Nomor 13/1/PB/2011 tanggal 5 Januari 2011 tentang Penilaian Kesehatan Bank Umum. Indikator penilai tingkat kesehatan bank tersebut tertera pada Surat Edaran Bank Indonesia Nomor 13/24/DPNP Tanggal 25 Oktober 2011. Penilaian tingkat kesehatan bank menggunakan struktur atau komponen CAMELS (Capital, Asset Quality, Management, Earning Power, Liquidity, dan Sensitivity to Market Risk). Selain metode CAMELS khusus bagi perbankan, deteksi potensi kebankrutan Perusahaan dapat dilakukan dengan model analisis Altman Z-Score Non Manufaktur.

Altman menggunakan empat rasio keuangan untuk menilai kecenderuangan perusahaan menjadi bangkrut atau tidak bangkrut dan menghitung nilai $\mathrm{Z}$ atau dikenal dengan Z-Score. Dalam model tersebut skor 2,90 merupakan ambang batas 
untuk perusahaan sehat. Jadi, perusahaan yang mempunyai skor di atas 2,90 dapat dikatakan sebagai perusahaan sehat. Sedangkan perusahaan yang mempunyai skor dibawah 1,20 akan diklasifikasikan sebagai perusahaan yang potensial bangkrut. Kemudian diantara 1,20 dan 2,90 diklasifikasikan sebagai perusahaan pada grey area (daerah kelabu).

$>$ Z-Score > 2,9 maka diklasifikasikan sebagai perusahaan yang sehat

> Z-Score 1,2 sampai 2,9 maka perusahaan tersebut berada pada area abu-abu (Grey)

$>$ Z-Score < 1,2 maka diklasifikasikan sebagai perusahaan yang berpotensi bangkrut

Dari perhitungan Altman Z-Score berdasarkan laporan keuangan tahun 2018 dan 2019 maka diperoleh hasil sebanyak $100 \%$ Perusahaan Perbankan BUMN berada di posisi Grey Area (Z-Score 1,2 sampai 2,9).

a. PT. Bank Negara Indonesia (Persero) Tbk

PT. Bank Negara Indonesia (Persero) Tbk pada tahun 2018 memiliki nilai ZScore sebesar $=2.42$ dan sedikit menurun di tahun 2019 menjadi ZScore $=2.38$. Kondisi kesehatan keuangan ini meningkat dibandingkan dengan tahun 2014 yakni nilai Z-Score = 2.2 dan tahun 2015 dengan nilai Z-Score $=2.2$ (penelitian yang dilakukan penulis dengan metode yang sama pada tahun 2017). Untuk rasio keuangan BNI mengalami sedikit peningkatan adalah pada rasio $\mathrm{X} 3$, sedangkan ratio $\mathrm{X} 1, \mathrm{X} 2$ dan $\mathrm{X} 4$, cenderung menurun. Walau dalam posisi abu-abu dan diprediksi tidak dalam posisi bangkrut, namun Bank BNI harus lebih berhati-hati agar tidak tergerus ke dalam posisi berpotensi bangkrut, dan harus meningkatkan kinerja keuangannya agar mengalami peningkatan pada semua yang di nilai ratio terutama ratio $\mathrm{X} 2$ sehingga dapat memasuki area kategori sehat.

\section{b. PT Bank Rakyat Indonesia (Persero) Tbk.}

Hasil analisis Altman Z-Score menunjukan bahwa bank BRI termasuk dalam grey areadengan Nilai Z-Score pada tahun 2018 sebesar $=2.24$, dan mengalami penurunan pada tahun 2019 menjadi $=2.19$. Kondisi kesehatan keuangan Bank BRI ini juga mengalam peningkatan dibanding tahun $2014=2.0$ dan tahun $2015=1,9$. Ratio yang mengalami sedikit peningkatan adalah ratio $\mathrm{X} 2$, dan ratio $\mathrm{X} 4$ sedangkan ratio $\mathrm{X} 1, \mathrm{X} 3$, cenderung turun. Bank BRI harus lebih bisa meningkatkan kinerja keuangannnya pada masa-masa mendatang agar jauh dari area potensi kebangkrutan dan dapat masuk dalam Area kategori sehat.

c. PT Bank Tabungan Negara (Persero) Tbk.

PT. Bank BTN memiliki nilai Z-score terendah dibanding perbankan BUMN lainnya. PT. Bank BTN juga dikategorikan sebagai perusahaan yang berada dalam Gray Area, dengan memiliki nilai z-score pada tahun 2018 sebesar $=2.07$ dan mengalam peningkatan di tahun 2019 menjadi = 2.19. Walaupun nilai Z-Score dari bank ini lebih rendah dari ketiga bank BUMN lainnya, namun kondisi kesehatan keuangan bank ini mengalami kemajuan yang cukup signifikan jika dibandingkan dengan tahun 2014 dan di tahun 2015, dimana pada tahun 2014 nilai Z-Scorenya $=0,9$ dan menurun di tahun 2015 menjadi $=0,7$. (dapat berpindah dari Distress Area kedalam Grey Area). Ratio X1, dan X2 mengalami kenaikan di tahun 2019, sedangkan ratio $\mathrm{X} 3$, dan $\mathrm{X} 4$ mengalami penurunan di tahun 2019. Kondisi ini mengharuskan pihak manajemen untuk secara terus menerus memperbaiki dan meningkatkan kinerja keuangannya dengan memperkuat ratio-ratio penilaian, agar tidak kembali pada 
Distress area pada masa-masa yang akan datang.

d. PT Bank Mandiri (Persero) Tbk.

PT. Bank Mandiri juga menempati posisi Grey Area, yakni memiliki nilai Z-score diantara 1.2 sampai 1.9. Bank ini di tahun 2018 memiliki nilai ZScore sebesar 2.40 dan pada tahun 2019 meningkat menjadi 2.56, (tertinggi diantara ketiga bank BUMN lainnya). Kesehatan keuangan bank Mandiri juga mengalami kemajuan yang cukup baik jika dibandingkan tahun 2014 dan 2015. Dimana ditahun 2014 Z-Score yang dimiliki Bank ini sebesar $=2.26$, dan di tahun $2015=$ 2,29. Keempat ratio yakni X1, X2, X3, dan X4 mengalami sedikit kenaikan di tahun 2019. Manajemen bank Mandiri harus meningkatkan kinerja keuangan pada masa-masa yang akan datang agar masuk dalam Area Sehat.

Terlepas dari hasil penelitian ini, penulis meyakini bahwa masih ada alat penilaian yang mungkin lebih efektif dan akurat, yang dapat dikembangkan dalam penelitian-penelitian lanjutan.

\section{KESIMPULAN}

1. Hasil analisis deteksi potensi kebangkrutan dengan menggunakan formula Altman $\mathrm{Z}$ Score non manufaktur, mengungkapkan bahwa ke empat perusahaan perbankan BUMN yakni PT. Bank BNI Tbk, PT. Bank BRI Tbk, PT. Bank Tabungan Negara (Persero) Tbk, dan PT. Bank Madiri, Tbk. berada dalam Gray Area. Pada tahun 2018 dan 2019. Pada tahun 2019 PT. Bank Mandiri, Tbk mempuyai nilai Z-Score tertinggi yak ni sebesar $=2.56$.

2. Rasio yang berpengaruh tehadap tingkat kesehatan Perbankan BUMN, seperti untuk ratio $\mathrm{X} 1, \mathrm{X} 2, \mathrm{X} 3$ dan $\mathrm{X} 4$ harus di perkuat dengan fokus pada pengendalian variabel utama yang mempengaruhi ratio-ratio tersebut. Current asset misalnya, sebaiknya diperkuat agar dapat menutupi current liabilities sehingga working capital yang dimiliki tidak menjadi negativ. Investasi pada piutang yang terlalu besar juga berbahaya sebab dapat mengakibatkan kinerja perusahaan menjadi terganggu. Apabila terjadi gangguan terhadap piutang maka hal tersebut akan mengganggu perusahaan karena secara tidak langsung itu akan berdampak pada penerimaan kas perusahaan di masa yang akan datang. Kemudian persediaan yang juga terlalu besar dapat menyebabkan perusahaan menjadi kurang likuid. Biaya-biaya operasional perusahaan juga perlu diperhatikan penggunaannya agar lebih efisien jangan sampai lebih besar daripada pendapatan yang dihasilkan oleh perusahaan.

\section{SARAN}

Untuk menganalisa deteksi potensi kebangkrutan Perbankan lebih baik disamping menggunakan metode Altman Z-score, juga dapat di lengkapi dengan metode lainnya seperti metode Springate dan metode analisis CAMEL, agar hasilnya lebih mendekati fakta.

\section{DAFTAR PUSTAKA :}

Ardani, Vesselina Sarifah, 2011. Analisis rasio Keuangan Dengan Menggunakan Metode Altman Untuk Mengukur Kesehatan Perusahaan Manufaktur Industri Makanan dan Minuman Yang Terdaftar Di Bursa Efek Indonesia, Skripsi. Unuversitas Sumatera Utara, Medan.

Baridwan, Zaki. 2010. Intermediate Accounting. Edisi 8. BPFE. Yogyakarta.

Harahap, Sofyan Safri. 2009. Analisis Kritis atas Laporan Keuangan. 
Jakarta : PT. Raja Grafindo Persada.

Hery, 2012. Mengenal dan Memahami Laporan Keuangan, CAPS, Jogjkarta

Ikatan Akuntan Indonesia, 2011. Pernyataan Standar Akuntansi Keuangan per Januari 2011, Jakarta

Kasmir, 2011. Analisis Laporan Keuangan. Catatan Keempat, PT. Raja Grafindo Persada, Jakarta.

Kholid, Abu, 2012, Altman Z-score: Model Untuk Memprediksi Kesulitan Keuangan Perusahaan, http://accounting.binus.ac.id (diakses tanggal 20 Mei 2015)

Sudana, Made I, 2011. Manajemen Keuangan Perusahaan Teori \& Praktik. PT Gelora Aksara Pratama. Surabaya

Rismawaty, 2011. Analisis Perbandingan Model Prediksi Financial Distress Altman, Springate, Ohlson dan Zmijewski (Studi Empiris pada Perusahaan Manufaktur yang Terdaftar di Bursa Efek Indonesia. Universitas Hasanuddin, Makassar

Rizki, 2014. ANALISIS PREDIKSI KEBANGKRUTAN, http://irmajhe.blogspot.com (diakses tanggal 19 Mei 2015)

Rofinus Leki, 2017 "Penerapan Altman ZScore dalam mengukur potensi kebangkrutan (Studi Kasus pada Perusahaan Perbankan BUMN Yang Terdaftar di Bursa Efek Ind0nesia Tahun 2014 dan Tahun 2015)".

Rofinus Leki, dkk, 2020 "“Penerapan Altman Z-Score dalam mengukur potensi kebangkrutan (Financial Distress) Studi Kasus pada PT.
Bank Tabungan Negara (Persero) Tbk Yang Terdaftar di Bursa Efek Indonesia (Data Laporan Keuangan Tahun 2016 dan Tahun 2017)". JIEB : Jurnal Ilmiah Ekonomi Bisnis

http://ejournal.stiepancasetia.ac.id /index.php/jieb. Jilid 6 Nomor 1 Maret 2020

Suciati, Amelia, 2012, Camels Dalam Perbankan, http://melzdsnih.blogspot.com (diakses tanggal 2 Agustus 2015)

Ulfah, Resti Amalia, 2012. Analisis

Penggunaan Altman Z-Score untuk engetahui Potensi Kebangkrutan PT.Sumalindo Lestari Jaya Tbk, Fakultas Ekonomi Universitas Mulawarman: Samarinda

Yoseph, 2011. Analisis Kebangkrutan dengan Metode Z-Score Altman, Springate dan Zmijewski Pada PT Indofood Sukses Makmur Tbk Periode 2005 - 2009, Jurnal Akuntansi. Universitas Kristen Maranatha.

www.idx.co.id 